\section{THE RÔLE OF FATS IN THE TREATMENT OF DISORDERS OF THE STOMACH. ${ }^{1}$}

\section{BY F. CRAVEN MOORE, M.D., M.Sc. VICT,}

M.R.C.P. LOND.,

HONORARY PHYSICIAN 'LO THE ANCOATS HOSPITAL, MANCHESTER; AND

R. L. FERGUSON, M.D. VIOT.,

LATE HOUSE PHYSICIAN TO THE ANCOA'LS HOSPITAL, MANCHESTER.

THE use of fat in the treatment of gastric disorders, not merely as a foodstuff, but with the idea of producing a definite therapeutic effect on the disordered secretory activity of the stomach, is of comparatively recent development, and is based on the recognition of the frequency with which excessive secretory activity of the gastric glands obtains as a pathological condition, and on the demonstration of the depressant action of fats on the activity of normal gastric secretion.

It had long been suspected that the presence of fats in the stomach interfered, in some way or other, with gastric digestion, a belief which was in some measure confirmed by the observation of Penzoldt, who found that a mixture of coffee and cream yielded a lower acidity of the stomach contents than coffee alone, and more conclusively by the later exact observations of Ewald and Boas who showed that the addition of bacon fat to the test breakfast associated with their names resulted in a prolongation of the period of gastric digestion and a marked diminution in the amount of free hydrochloric acid in the stomach contents. As at that period it was the prevalent belief that any deviation from the normal in the functional activity of the stomach must be in the direction of deficiency, and that the subjective manifestations of such deviation depended upon organic acid and gaseous fermentations initiated as the immediate consequence of deficiency in the antiseptic hydrochloric acid and stagnation of the contents from deficient motor power, the results of Ewald and Boas served but to emphasise the belief that the administration of fats in gastric disorders, and particularly in such as accorded with the type of acid dyspepsia, was contra-indicated in that they would induce further depression of functional activity and provide a possible source for the noxious acids themselves.

The investigations of the German school, and particularly those of Riegel and his followers, into the secretory activity of the stomach in gastric disorders demonstrated not only that excessive secretory activity of the gastric glands could obtain as a pathological condition, but that such was even more frequent than defective activity, and that in the so-called acid dyspepsia the frequently excessive acidity of the stomach contents was due not to organic acids but to an abnormally high content in hydrochloric acid itself. This conception of the disorders of secretory activity bas been generally confirmed in its main theses, and in this country, although belief in the acid dyspepsia of organic acid fermentation still lingers, the frequency of pathological hypersecretion is now well recognised. To the brilliant investigations of Pawlow and his co.workers we are indebted for the basis of a more accurate appreciation of the nature and origin of these disorders of functional activity and also for suggestions as to their rational treatment. The observations of Ohigin, Lobasoff, Wirschubsky, Lintwareff, and Sokoloff in the laboratories of Pawlow established that the liquid fats, olive oil and cream, were devoid of any excitative influence on gastric secretion when introduced directly into the stomach of the dog, and that their presence exerted an inbibitory influence on the normal energy of the secretory process excited by other foodstuffs.

Following on this demonstration of the depressant action of fats on the secretory activity of the stomach in the dng. certain continental observers, notably Stranss, von Aldor, Backmann, Akimow Peretz, Piontkowski, Cohnheim, Walko, and others, began the administration of liquid fats in such morbid conditions of the human stomach as were associated with hyperacidity of the stomach contents. At first cream and butter were employed by Backmann, then emulsions of

A paper communicated to the Medical Section of the Royal Society of Medicine on Nov. 23rd, 1909 almond oil by Akimow-Peretz and Strauss and von Aldor, and, lastly, pure olive oil by Cohnheim, Walko, and others. The results recorded were, with but few exceptions (Ewald, Fischl, Blum), so beneficial in alleviating the subjective discomfort and in improving the nutrition of the patient that the method well-nigh attained the dignity of an "oil-cure." Our own observations have confirmed in great measure the beneficial results of the administration of liquid fats in conditions of hyperacidity claimed by these previous investigators. They have demonstrated perhaps more completely than had been previously done the marked effect of such fats in diminishing the acidity of the stomach contents, and they have opened up some problems for further investigations.

It has been my (F. C. M.) practice at the Ancoats Hospital to include in the routine examination of such cases as mani. fested symptoms of gastric disorder (unless contra-indicated) a simple estimation of the secretory activity of the stomach. The method employed consists in the administration first thing in the morning on the empty fasing stomach of a modified Ewald-Boas test breakfast, modified to obtain what I regard as being of prime importance for comparative results, constancy of physical character and composition, consisting of 10 ounces of weak tea withont milk or sugar, and four breakfast biscuits (Huntley and Palmer), which average about 30 grammes. The stomach contents are removed after an interval of one hour, the volume and appearance noted, and in the filtrate the amount of free hydrochloric acid and the total acidity are estimated approximately by titration with decinormal sodium hydrate-solutions of dimethylamidoazobenzol and phenol-phthalein respectively being employed as indicators. The results are stated in terms of the number of cubic centimetres of decinormal soda sulution required to neutralise the respective acidities in 100 cubic centimetres of the filtrate. The peptic power of the filtrate is estimated by the length of a column of coagulated egg" albumin digested in 24 hours at $375^{\circ} \mathrm{C}$. according to the method of Mett, and in some cases an approximation to the relative content in pepsin itself is made by the dilution method of Schiff and Nierstein.

This systematic investigation of the secretory activity of the stomach in all cases with manifestations of gastric disorder has demonstrated the frequency with which excessive secretion obtains, a feature which becomes obvious in the series of control analyses in the accompanying tables on comparing the values for free $\mathrm{HCl}$ and total acidity with the normal values, $20-40$ and $40-60$ respectively, for such a meal.

With the appearance of Cohnheim's paper on the employment of large doses of olive oil this method of treatment was tried in a few cases, and with such obviously beneficial results, not only in diminishing the acidity of the stomach contents, but also on the subjective discomfort and on the general nutrition of the patient, that further investigation of the influence of fats appeared desirable. In some 62 cases in which there were subjective manifestations of gastric disorder, either with or without indications of organic disease of the stomach, the effect of the administration of oil of sweet almonds on the secretory activity of the stomach was determined. On consecutive days a plain test breakfast and a test breakfast preceded 30 minutes by one ounce of almond oil was given, and in the stomach contents the free $\mathrm{HCl}$ and the total acidity were estimated; in certain of the cases the digestive power of the stomach contents (peptic and tryptic) was also determined by the method of Mett. The stomach contents after the oil breakfast separated on standing into three layers-oil on the surface, the fluid contents with its granular sediment below, and between the two a narrow layer of emulsified oil, and but for the presence of the oil the contents were similar in appearance to those after the control meal ; in no instance was there any evidence of the presence of hile pigments or of variations in the mucous content, and the quantity varied quite irregularly, being in some greater in others less than in the control.

The results of the analyses (see table) expressed in averages where a series of observations were made on any one case, show without exception that the administration of oil is associated with a marked reduction in the acid values, free $\mathrm{HCl}$ and total acidity, of the stomach contents. Although it is well recognised that in any individual, normal or otherwise, the acid values of the stomach contents, removed at a 


\begin{tabular}{|c|c|c|c|c|c|c|c|}
\hline \multicolumn{8}{|c|}{ Gastrio Uloer. } \\
\hline \multirow{2}{*}{ No. } & \multirow{2}{*}{$\begin{array}{l}\text { Sex and } \\
\text { age. }\end{array}$} & \multicolumn{2}{|c|}{ Plain T.B. } & \multicolumn{2}{|c|}{ Oil T. B } & \multicolumn{2}{|c|}{ Difference. } \\
\hline & & $\mathrm{HCl}$. & .A. & $\mathrm{HCl}$. & T.A. & $\mathrm{HCl}$. & T.A. \\
\hline 1 & M., 48 & 46 & 82 & 37 & 73 & 9 & 9 \\
\hline 2 & M., 33 & 40 & 80 & 37 & 60 & 3 & 20 \\
\hline 3 & M., 32 & 40 & 65 & 31 & 52 & 9 & 13 \\
\hline 4 & F., 37 & 13 & 34 & Trace. & 18 & 13 & 16 \\
\hline 5 & F., 28 & 71 & 95 & 52 & 74 & 19 & 21 \\
\hline 6 & E., 38 & 60 & 90 & 48 & 82 & 12 & 8 \\
\hline 7 & F., 26 & 70 & 100 & 45 & 64 & 25 & 36 \\
\hline 8 & F., 40 & 35 & 51 & 30 & 42 & 5 & 9 \\
\hline 9 & F., 27 & 65 & 90 & 41 & 62 & 24 & 28 \\
\hline 10 & M., 25 & 49 & 70 & 42 & 50 & 7 & 20 \\
\hline 11 & F., 24 & 70 & 89 & 35 & 53 & 35 & 36 \\
\hline 12 & F., 30 & 65 & 90 & 39 & 58 & 26 & 32 \\
\hline 13 & F., 22 & 42 & 60 & 16 & 30 & 26 & 30 \\
\hline 14 & F., 28 & 46 & 65 & 32 & 44 & 14 & 21 \\
\hline 15 & M., 60 & 40 & 71 & 25 & 56 & 15 & 15 \\
\hline 16 & M., 64 & 37 & 86 & 28 & 52 & 9 & 34 \\
\hline 17 & M., 46 & 40 & 58 & 36 & 49 & 4 & 9 \\
\hline 18 & F., 24 & 30 & 56 & 12 & 32 & 18 & 24 \\
\hline 19 & F., 47 & 56 & 78 & 32 & 58 & 24 & 20 \\
\hline 20 & F., 42 & 47 & 64 & 10 & 22 & 37 & 42 \\
\hline 21 & M., 28 & 48 & 66 & 44 & 62 & 4 & 4 \\
\hline 22 & M. , 18 & 48 & 74 & 3 & 20 & 45 & 54 \\
\hline 23 & M., 0 & 50 & 74 & 45 & 72 & 5 & 2 \\
\hline 24 & M., 40 & 34 & 60 & 28 & 53 & 6 & 7 \\
\hline 25 & F., 24 & 5 & 2 & 15 & 22 & 30 & 40 \\
\hline 26 & M., 28 & 0 & 8 & 32 & 42 & 28 & 36 \\
\hline
\end{tabular}

Duodenal Ulcer.

\begin{tabular}{r|r|r|l|l|l|l|r}
27 & M., 54 & 42 & 6 & 30 & 56 & 12 & 9 \\
28 & M., 30 & 48 & 64 & & 33 & 24 & 31 \\
29 & M., 50 & 4 & 54 & 14 & 30 & 20 & 24
\end{tabular}

Carcinoma of Stomach.

\begin{tabular}{r|r|r|r|r|r|r|r}
30 & M., 67 & 18 & 34 & 10 & 20 & 8 & 14 \\
31 & M., 48 & 0 & 14 & 0 & 12 & - & 2 \\
32 & M., 67 & 12 & 18 & 0 & 8 & 12 & 10
\end{tabular}

\section{Nervous Dyspepsia.}

\begin{tabular}{r|r|r|r|r|r|r}
., 28 & 8 & 49 & 8 & 18 & 20 & 31 \\
F., 22 & 39 & 55 & 17 & 38 & 22 & \\
F., 32 & 60 & & 34 & 50 & 26 & 28 \\
M., 30 & 32 & 52 & 20 & 40 & 12 & 12
\end{tabular}

Dilatation of Stomach (Atonic).

\begin{tabular}{l|r|r|r|r|r|r|r}
37 & M., 58 & 34 & 70 & 10 & 35 & 24 & 35 \\
38 & F., 19 & 22 & 45 & 18 & 34 & 4 & 11 \\
39 & F., 57 & 20 & 42 & 15 & 40 & 5 & 2 \\
40 & M., 38 & 43 & 69 & 30 & 63 & 13 & 6 \\
41 & F., 59 & 30 & 54 & 10 & 26 & 20 & 28 \\
42 & M., 42 & 12 & 32 & Trace. & 14 & 12 & 18 \\
43 & M., 35 & 28 & 46 & 10 & 25 & 18 & 21
\end{tabular}

\begin{tabular}{l|l|l|l|l|l|r|r}
\multicolumn{8}{|c}{ Alooholism. } \\
\hline 44 & M., 38 & 27 & 50 & 15 & 32 & 12 & 18 \\
45 & M., 37 & 58 & 98 & 52 & 85 & 6 & 13 \\
46 & M., 45 & 16 & 41 & 10 & 34 & 6 & 7 \\
47 & M., 24 & 28 & 54 & Trace. & 18 & 28 & 36 \\
48 & M., 39 & 22 & 36 & 10 & 24 & 12 & 12 \\
49 & M., 40 & 43 & 68 & 32 & 60 & 11 & 8 \\
50 & F. & 30 & 56 & 13 & 37 & 17 & 19 \\
51 & M., 54 & 20 & 32 & Trace. & 12 & 20 & 20 \\
52 & M., 60 & 45 & 67 & 39 & 62 & 6 & 5
\end{tabular}

\section{Constipation.}

\begin{tabular}{l|l|l|l|l|l|l|l}
58 & F., 67 & 20 & 40 & 16 & 32 & 4 & 8 \\
54 & M., 36 & 14 & 48 & 10 & 40 & 4 & 8 \\
\hline
\end{tabular}

Misocllaneous.

\begin{tabular}{|c|c|c|c|c|c|c|c|c|}
\hline \multirow{2}{*}{ No. } & \multirow{2}{*}{$\begin{array}{l}\text { Sex and } \\
\text { age. }\end{array}$} & \multirow{2}{*}{ Diaguosis. } & \multicolumn{2}{|c|}{ Plain T.B. } & \multicolumn{2}{|c|}{ Oil T.B. } & \multicolumn{2}{|c|}{ Difference. } \\
\hline & & & $\mathrm{HCl}$. & T.A. & $\mathrm{HCl}$. & T.A. & $\mathrm{HCl}$. & T.A. \\
\hline 55 & M., 35 & Gastritis. & 28 & 46 & 10 & 25 & 18 & 21 \\
\hline 56 & M., 27 & Influenza. & 35 & 59 & 29 & 50 & 6 & 9 \\
\hline 57 & M., 55 & Aortic disease. & 35 & 52 & 26 & 46 & 9 & 6 \\
\hline 58 & M., 26 & Mitral disease. & 35 & 68 & 10 & 43 & 25 & 25 \\
\hline 59 & M., 64 & Mitral disease. & 50 & 65 & 18 & 35 & 32 & 30 \\
\hline 60 & F., 37 & Severe anæmia. & 17 & 42 & 11 & 36 & 6 & 6 \\
\hline 61 & M., 67 & Phthisis. & 40 & 57 & 17 & 44 & 23 & 13 \\
\hline 62 & M., 49 & Phthisis. & 42 & 62 & 24 & 45 & 18 & 17 \\
\hline
\end{tabular}

T.B. = test breakfast. $\quad$ T.A. = total acidity.

Tabie of Averages.

\begin{tabular}{|c|c|c|c|c|c|}
\hline \multirow{2}{*}{ Diagnosis. } & \multirow{2}{*}{ No. } & \multicolumn{2}{|c|}{ Plain T.B. } & \multicolumn{2}{|c|}{ Oil T.B. } \\
\hline & & HCl. & T.A. & $\mathrm{HCl}$. & T.A. \\
\hline $\begin{array}{llll}\text { Total cases } & \ldots & \ldots & \ldots\end{array}$ & 62 & $38 \cdot 1$ & $60 \cdot 7$ & $23 \cdot 3$ & 42 \\
\hline Gastric ulcer $\quad \ldots \quad \ldots$ & 26 & $48 \cdot 7$ & $72 \cdot 5$ & $30 \cdot 5$ & 50 \\
\hline Duodenal ulcer $\ldots \quad \ldots$ & 3 & 41 & 61 & 23 & 40 \\
\hline $\begin{array}{llll}\text { Carcinoma } & \ldots & \ldots & \ldots\end{array}$ & 3 & 10 & ك́ & $3 \cdot 3$ & $13 \cdot 3$ \\
\hline Nervous dyspepsia ... & 4 & 40 & $58 \cdot 5$ & 20 & $36 \cdot 5$ \\
\hline Dilatation of stomach & 7 & 26 & 51 & $13 \cdot 2$ & 34 \\
\hline Alcoholism $\quad \ldots \quad \ldots \quad \ldots$ & 9 & 32 & $55 \cdot 8$ & 19 & $40 \cdot 4$ \\
\hline Constipation ... $\quad \ldots \quad \ldots$ & 2 & 17 & 44 & 13 & 36 \\
\hline Miscellaneous $\quad \ldots \quad \ldots$ & 8 & $35 \cdot 2$ & 56 & 18 & $40 \cdot 5$ \\
\hline
\end{tabular}

definite time after a meal of constant composition, vary within somewhat wide limits, yet the constancy with which they are diminished after the exhibition of oil in so large a number of cases precludes the possibility of coincidence.

The effect, though constant, presents some interesting variations in degree not only in the several types of gastric disorder but also in the same type and the same individual on different occasions. On averaging the results in each of the several series it appears that the greatest absolute diminution in the acid values after the administration of oil obtains in those which present the higl-not, average acidities with the plain test breakfast, and, as apuviurs from a comparison of the average results, in the cases of gastric ulcer, duodenal ulcer, and nervous dyspepsia, irrespective of the presence or absence of any lesion of the stomach. In the individual cases also this is true of the majority; thas in 12 cases with a free $\mathrm{HCl}$ value of 50 or more the average absolute diminution of this value is 20 , and in all but 4 the individual diminution ranges from 24 to 35 .

In the cases on which a series of observations were made it was noted that whilst the diminution in the acidity was invariable it differed in degree on different occasions, and further, what is of particular interest, the effect of the oil was apparently linited to the period immediately following its administration; in no instance was there any evidence of its having a more enduring effect on the acid values of the stomach contents. The averages, and also the majority of the individual observations, further show that the absolute diminution of the total acidity exceeds that of the free $\mathrm{HCl}$. This result is difficult of interpretation, since it apparently depends on a diminution of other factors than the $\mathrm{HCl}$, free or combined (assuming the latter to remain approximately constant with the constant proteid content of the test meal), which contribute to the total acidity of the stomach contents, and which it might be anticipated would be increased by the liberation of fatty acids in the splitting of the neutral fat by the hydrochloric acid and the possible gastric lipase.

Turning to the peptic activity of the stomach contents it was found in 12 cases in which observations were made that the digestive power was diminished with the acid values, a result in part, no doubt, of the deficiency in $\mathrm{HCl}$, but also, as shown by the dilution method, of an absolute diminution 
in the peptic content of the filtrate, and which is obvious in all but No. 25 of the following six observations.

\begin{tabular}{l|c|r|r|r|r|r|r}
\hline No. & Test-meal. & IICl. & $\begin{array}{c}\text { Total } \\
\text { acidity. }\end{array}$ & & & Pepsin.* & Trypsin. \\
\hline 34 & & & & $a$ & $b$ & $c$ & \\
\hline 36 & Plain. & 45 & 62 & 42 & 27 & 9 & 0 \\
& Oil. & 15 & 22 & $2 \cdot 25$ & 64 & 12 & 0 \\
& Plain. & 60 & 78 & 182 & 144 & 42 & 0 \\
33 & Oil. & & 42 & 81 & 41 & 12 & 0 \\
& Plain. & 48 & 64 & 182 & 144 & 30 & 0 \\
34 & Oil. & 24 & 33 & 41 & 38 & 6 & 0 \\
& Plain. & 28 & 49 & 72 & 67 & 27 & 0 \\
& Oil. & 8 & 18 & - & 13 & 1 & 0 \\
& Plain. & 39 & 55 & 60 & 81 & 22 & 0 \\
& Oil. & 17 & 38 & 25 & 36 & 17 & 0 \\
& Plain. & 60 & 78 & 225 & 132 & 36 & 0 \\
& Oil. & 34 & 50 & 41 & 84 & 30 & 0 \\
\hline
\end{tabular}

* $a$, Filtrate alone. $b$, Fourfold dilution with $\frac{\mathrm{N}}{10} \mathrm{HCl}, c$, Sixteenfold dilution with $\frac{\mathrm{N}}{10} \mathrm{HCl}$.

In three cases the oil was given simultaneously with the testmeal and resulted in a similar diminution of the acid values of the stomach contents.

The explanation of the phenomena following the administration of fats on a subsequent meal is a problem for the exact methods of experimental physiology rather than for the methods of clinical research. The investigations which have dealt with the matter by the exact methods of Pawlow leave it still in doubt whether the observed phenomena are due to a true depression of gastric secretion or to dilution and neutralisation by regurgitant alkaline duodenal contents.

Pawlow from his earlier experiments, in which the introduction of olive oil directly into the stomach of the dog by means of a sound resulted in a marked depression of secretory activity as tested by a subsequent meal of flesh, concluded that fat inhibits the normal energy of the secretory process, that the inhibition is central by reflex stimulation of the inhibitory nerves of the glands or the inbibitory centres of these nerves, and is not a mere mechanical effect of the covering over the mucous membrane and preventing excitation of the nerve endings. With the object of testing whether oil might act in some such mechanical way we made a number of observations in which oil was replaced by petroleum, but in no instance was there any diminution of the acid values of the stomach contents.

The later experiments of Sokoloff on animals with gastric and duodenal fistulæ showed that the presence of undigested fat in the duodenum suffices to inhibit the secretion of gastric juice and he concluded that the inhibitory effect of fat originates chiefly from the surface of the duodenal mucous membrane and not from the stomach. Boldyreff, on the other hand, following up some observations of Damaskin, found that the introduction of oil into the stomach of the dog led to an undoubted flow of bile, pancreatic juice, and intestinal juice into the stomach. Experimenting on himself and one of his associates, he found that the stomach contents removed one or one and a half hours after the ingestion of 80 cubic centimetres of a 2 per cent. solution of oleic acid in olive oil contained trypsin and a lipase of pancreatic origin. These investigations have been repeated on the human subject by already a considerable number of observers, Volhard, Faubel, Mohr, Schittenhelm, Levinsky, Molnar, Mahlenbrey, and others, but with another object-namely, of obtaining viâ the stomach a sample of the duodenal contents in order to estimate the functional capacity of the pancreas, and in the majority of instances it has been found that the administration of oil on the empty stomach sufficed to cause a regurgitation of the duodenal contents into the stomach.

In nine observations in which we administered 100 cubic centimetres of oil on the empty stomach, in four only where the oil was withdrawn after the lapse of half an hour was bile pigment present in the mixture, which was acid in reaction, devoid of $\mathrm{HCl}$ in a free state, contained pepsin, and in one case gave a very slight tryptic digestion. In the other five cases the oil was allowed to remain in the stomach for an hour, and in four of these neither bile pigment nor trypsin was present in the mixture, which contained a small amount of free $\mathrm{HCl}$ and pepsin, and in one there was a faint greenish tinge of bile pigment. But, as already mentioned, in no instance was the presence of bile pigments or trypsin noted in the stomach contents after an oil breakfast.

Whatever the explanation may be, it remains that the neutral liquid fats administered before food lead to a diminution of the subsequent acidity of the stomach contents, the more so the greater the tendency of the secretory activity of the stomach to exceed the normal. Clinically, our experience of the administration of fats, such as cream, butter, almond oil, in conditions in which hyperacidity of the stomach contents has been found to exist, has shown this action of fats to be associated with a very definite amelioration of the subjective manifestations of the condition. In simple forms of hyperacidity depending on slight degrees of digestive hypersecretion (the so-called hyperchlorhydria of Riegel) the addition of cream and butter in abundance to the diet, with a diminution of the starches, will often suffice to remove the subjective manifestations. It is only in the more severe types, and particularly the severe degrees of digestive or continuous hypersecretion so commonly associated with chronic ulcer about the pylorus or duodenum, in which heartburn, acid pyrosis, the sudden gnawing pain in the epigastrium ascribed to pyloric spasm, and the vomiting of acid fluid, that the administration of almond oil is undertaken, and then in doses of 1 ounce first thing in the morning and repeated before subsequent meals if necessary. This method has proved of value in not only alleviating the symptoms which follow the digestion of food in the stomach, but also in contributing very considerably to the nutrition of the patient, and is certainly preferable to the sole use of alkalies for the purpose of neutralising the hyperacid stomach contents and so obtaining relief from the symptoms. In no case have we found that oil so administered has been badly tolerated or in any way proved objectionable.

Bibliography.-Ageron: Munchener Medicinische Wochenschrift, 1902, No. 30. Akimow-Peretz: Wratsch, 1898, No. 4. Backmann: Zeitschrift fur Klinische Medicin, 1900, vol. x1., p. 224. Boldyreff: Archiv fur die gesammte Physiologie, 1908, vol. exxi., p. 13. Bloch : Archiv für die Verdauungskrankheiten, 1907, vol. xiii., p. 606. Blum : Berliner Klinische Wochenschrift, 1905, Nos. 20 and 21. Cohnheim: Zeitschrift für Klinische Medicin, 1904, vol. lii., p. 110. Ewald and Boas: Virchow's Archiv, 1886, vol. civ., p. 271. 'Faubel and Volhard : Mïnchener Medicinische Wochenschrift, 1907, p. 403. Fischl : Prager Medicinische Wochenschrift, 1903, Nos. 10 and 12. Strauss and Aldor: Zeitschrift fur Diätetische und Physische Therapie, 1898, vol. i., p. 117. Walko : Zentralblatt für die innere Medicin, 1902, No. 45.

\section{A FURTHER NOTE UPON THE RELATION- SHIP BETWEEN AVIAN AND HUMAN} TUBERCULOSIS.

By S. G. SHATTOCK, F.R.O.S. EnG., AND

LEONARD S. DUDGEON, F.R.C.P. LOND. (From the Pathological Laboratories of St. Thomas's Hospital.)

IN the Proceedings of the Royal Society of Medicine, Pathological Section, December, 1907, we published. in conjunction with Dr. C. G. Seligmann and Dr. P. N. Ptnton, the results of an investigation upon the above subject. Our conclusions as therein stated were as follows.

The human tubercle bacillus is pathogenic to the pigeon in a very limited degree only. It sets up no disease of the intestine or of the abdominal viscera when introduced (in sputum) with food into the alimentary tract, even for prolonged periods (six months) and in excessive quantities. It sets up a local or a local and glandular disease only, in the pigeon, when injected (in sputum) into the muscles or subcutaneous tissues. It sets up a local or a local and glandular disease only in the pigeon when injected into the muscles or subcutaneous tissues from the organs of guinea-pigs which have been infected by innculation with human sputum. The avian tubercle bacillus as tested from various kinds of birds is pathogenic to the guinea-pig in a very limited degree. The human bacillus has not, so far, in our hands, proved convertible into the avian by innculation into the bird-i.e. the bacilli have not proved identical. 